\title{
Periodontal health and diabetes awareness among Saudi diabetes patients
}

\author{
This article was published in the following Dove Press journal: \\ Patient Preference and Adherence \\ 2 February 2015 \\ Number of times this article has been viewed
}

\author{
Maha A Bahammam \\ Department of Periodontology, \\ King Abdulaziz University Faculty \\ of Dentistry, Jeddah, Kingdom \\ of Saudi Arabia
}

Purpose: This study aimed to examine diabetic patients in Jeddah, Saudi Arabia, regarding their general diabetic and oral health-related awareness and practices, their awareness of the association of diabetes with periodontal disease, and their sources of diabetes-related information.

Methods: Diabetic patients $(n=454)$ who were receiving care at the diabetes clinic in King Abdulaziz University Hospital, Jeddah, Saudi Arabia, from October 2013 to May 2014, completed a six-part questionnaire assessing their sociodemographic characteristics, general and oral health awareness and practices, and sources of diabetes-related information. Descriptive statistics were used to report the results.

Results: The responses indicated inadequate health-related practices in the surveyed group: $22.2 \%$ brushed their teeth twice daily, $73.6 \%$ never flossed their teeth, and while $80.2 \%$ visited a physician in the past year, only $12.6 \%$ visited a dentist during the same year. Of the respondents, $94.8 \%$ reported that they had never received advice on oral hygiene tasks in relation to diabetes from a health professional. Awareness about the diabetes and periodontal disease association was limited: $46.7 \%$ knew that diabetics have gum problems more often if their blood sugar stays very high, and only $21.8 \%$ knew that gum disease makes it harder to control blood sugar in diabetic patients. A significant association $(P<0.05)$ was found between a higher level of education and greater general and oral awareness, as well as a significant association $(P<0.05)$ between longer duration of disease, regular exercise, and regular visits to the physician and awareness about diabetes mellitus. Additionally, a significant association $(P<0.05)$ was found between regular dental visits and both periodontal disease and diabetes awareness. Family and friends were the main source of diabetes-related information, and the Internet was the least likely source.

Conclusion: Customized educational programs should be planned for diabetic patients according to community needs.

Keywords: periodontal health, diabetes, patients, awareness, Saudi Arabia

\section{Introduction}

Diabetes mellitus encompasses a group of metabolic disorders that result in acute and chronic complications due to the absolute or relative lack of insulin. Diabetes has reached epidemic proportions worldwide, and its prevalence is increasing rapidly. In 2000 , an estimated $2.8 \%$ of all age groups worldwide were suffering from diabetes. This number is estimated to be $4.4 \%$ in $2030 .{ }^{1}$

In Saudi Arabia, diabetes mellitus has one of the highest prevalence rates. The overall prevalence of diabetes mellitus among Saudi adults of both sexes in rural as well as urban communities is $23.7 \%$, with $26.2 \%$ being males and $21.5 \%$ females, as reported by a community-based national epidemiological health survey published in $2004 .^{2}$

Long-term poor glycemic control in diabetes is the principal cause of major complications including diabetic nephropathy, retinopathy, coronary heart disease, and strokes. ${ }^{3}$
Correspondence: Maha A Bahammam Department of Periodontology, King Abdulaziz University Faculty of Dentistry, PO Box 80209, Jeddah 21589, Kingdom of Saudi Arabia

Tel +966505303227

Fax +966 I 26403316

Email mahabahammam@kau.edu.sa 
Moreover, studies indicate that diabetic patients are two to three times more likely to develop periodontal disease $\mathrm{e}^{4-8}$ and display a greater severity of periodontal disease. ${ }^{9}$

An extensive body of research has proven a bidirectional relationship between periodontal disease and diabetes. ${ }^{10,11}$ Uncontrolled diabetes with poor glycemic control is a risk factor for severe periodontitis. The treatment of periodontitis improves glycemic control. ${ }^{12}$ Considering this important relationship between periodontal disease and diabetes, effective behaviors to prevent and control periodontal disease such as brushing, flossing, and routine dental visits not only have a positive impact on improving periodontal health ${ }^{13}$ but must also be considered as integral for diabetic patients' health. ${ }^{14}$

Several studies have investigated the awareness of diabetic patients regarding their periodontal health and the increased risk for periodontal disease. In a controlled study conducted in Sweden, 83\% of diabetic patients were found to be unaware of the link between periodontal disease and diabetes. ${ }^{15}$ Moreover, a cross-sectional study that was conducted in 38 states in the USA showed that diabetic patients are less concerned with their oral health and were less likely to have seen a dentist than nondiabetic patients. ${ }^{16}$ Another study conducted in the USA involving 390 patients with diabetes found that only $18.2 \%$ recognized that their oral health might be affected by diabetes. ${ }^{17}$ A community trial in Finland concluded that self-reported twice-daily tooth brushing is less frequent in diabetic patients than in nondiabetic patients. ${ }^{18}$ In the Arab countries, a study conducted on a random sample of 405 diabetic patients in Jordan showed that approximately $48 \%$ were aware that diabetic patients are more susceptible to periodontal diseases and oral health complications, and approximately a third (38\%) knew that periodontal treatment may help in controlling diabetes. ${ }^{19}$

In Saudi Arabia, currently, little is known about the knowledge of risk for periodontal disease and the awareness of oral health in diabetic patients. In one survey conducted in Riyadh, Saudi Arabia, of female Saudi diabetic patients assessing their knowledge and attitude regarding oral health, it was found that the majority of these diabetic patients lacked knowledge about the relationship between diabetes and periodontal health. ${ }^{20}$ A more recent study conducted in Abha, Saudi Arabia, illustrated that there is deficiency in the awareness and dental health knowledge among diabetic patients. The results showed that $52.3 \%$ of the participants were not aware that diabetic patients are more susceptible to oral diseases. ${ }^{21}$

Given these findings and the alarming high prevalence of diabetes in Saudi Arabia, further research is needed to assess the association of periodontal disease and diabetes and to develop preventive strategies to control this problem. The aim of this study was to examine diabetic patients for the following: 1) general diabetic and oral health-related awareness and practice; 2) awareness of diabetes and its association with periodontal disease; 3 ) and sources of diabetes-related information in Jeddah, Saudi Arabia.

\section{Materials and methods \\ Sample}

This study was a cross-sectional descriptive survey of 454 subjects with known diagnosis of diabetes mellitus who were registered at the diabetes clinic in King Abdulaziz University (KAU) Hospital, Jeddah, Saudi Arabia. The majority of patients attending this hospital are Saudis from a mixture of urban and rural communities, with varying socioeconomic backgrounds. The study was conducted from October 2013 to May 2014. Diabetic patients needed to fulfill the following two conditions to be included in this study: 1) the presence of at least one natural tooth in the patient's mouth and 2) the patient had been diagnosed with diabetes for at least 6 months. Diabetic medical personnel or patients with obvious physical or mental illnesses were excluded from this study. Patients of all age groups were included in the sample.

\section{Questionnaire}

A structured questionnaire was designed based on a thorough review of the literature on diabetes and periodontal disease. ${ }^{22-27}$ The questionnaire consisted of six parts. The first part of the survey assessed sociodemographic characteristics (sex, age, nationality, and education). The second part assessed participants' medical history including type of diabetes, medications used, duration, and family history of the disease. The third part assessed participants' general health and oral hygiene practices including participants' physical activities (ie, exercise), recent testing for blood glucose, regularity of visits to physician and dentist, brushing and flossing frequency, and other questions concerning previous advice to participants by medical personnel. The fourth part assessed participants' general awareness of diabetes concerning diet, causes of diabetes mellitus, types of diabetes, and blood glucose level. The fifth part assessed the periodontal-diabetes association, including questions addressing the bidirectional relation between periodontitis and diabetes mellitus and its relationship to smoking and to blood glucose levels. Items in the fourth and fifth parts were multiple-choice questions with three answer options for every given statement: true, false, or do not know. On the sixth and last parts of the questionnaire, participants were questioned regarding their sources of diabetes information. Options given 
in this section were friends or family, a health care provider, newspapers, magazines or books, television, the Internet, or school. The questionnaire was reviewed for appropriate wording by expert colleagues at KAU. Subsequently, the questionnaire was piloted on 30 patients to determine time required and readability. The study protocol was approved by the Research Ethics Committee of KAU Faculty of Dentistry. All diabetic patients entered the study voluntarily, following an explanation of its purpose and objectives. Informed verbal consent was obtained from each eligible participant prior to data collection. The data were collected by interviewing the participants; investigators asked the questions verbally and completed the form. Interviewers were trained to achieve consistency among them. Privacy of the patients was ensured, and at the end of questioning, the patients were informed about the impact of their systemic condition on oral health and vice versa.

\section{Statistical analysis}

Descriptive statistics were used to report the results regarding the participants' sociodemographic data, medical history, participants' general and oral health awareness and practices, participants' awareness and healthy behavior, and participants' sources of diabetes-related information.

Wilcoxon Mann-Whitney test was used for comparison of the awareness distributions in the case of two groups, and Kruskal-Wallis test was used in the case of more than two groups. All tests were two sided with $P<0.05$ set as the significance level. All analyses were conducted using SPSS version 16 (SPSS Inc., Chicago, IL, USA).

\section{Results}

\section{Distribution of the study population}

Sociodemographic characteristics of the participants A total of 454 ( 231 males and 223 females) out of 522 registered diabetic patients completed the diabetes awareness assessment questionnaire for a response rate of $87 \%$. The highest percentage of the respondents were between 40 years and 59 years of age (41.4\%), and 39.6\% were between 20 years and 39 years of age. With regard to their nationality, $85.7 \%$ were Saudis, and $14.3 \%$ were non-Saudis; $45.8 \%$ of the participants had college education (Table 1).

\section{Medical history}

Most of the participants suffered from type 2 diabetes (85.8\%), and only $14.2 \%$ suffered from type 1 . The majority were taking oral hypoglycemic medication (69.3\%), and the rest were taking either insulin alone (19.4\%) or both insulin and oral hypoglycemic $(11.3 \%)$. Regarding the length of time since
Table I Description of study population

\begin{tabular}{|c|c|c|}
\hline $\begin{array}{l}\text { Sociodemographic } \\
\text { characteristics of participants }\end{array}$ & $\mathbf{n}$ & $\%$ \\
\hline \multicolumn{3}{|l|}{ Sex } \\
\hline Male & 231 & 50.9 \\
\hline Female & 223 & 49.1 \\
\hline \multicolumn{3}{|l|}{ Age (years) } \\
\hline$<20$ & 51 & 11.2 \\
\hline$\geq 20$ & 180 & 39.6 \\
\hline$\geq 40$ & 188 & 41.4 \\
\hline $60+$ & 35 & 7.7 \\
\hline \multicolumn{3}{|l|}{ Nationality } \\
\hline Saudi & 389 & 85.7 \\
\hline Non-Saudi & 65 & 14.3 \\
\hline \multicolumn{3}{|l|}{ Education } \\
\hline Below college & 180 & 39.6 \\
\hline College & 208 & 45.8 \\
\hline Postgraduate & 66 & 14.5 \\
\hline \multicolumn{3}{|l|}{ Medical history } \\
\hline \multicolumn{3}{|l|}{ Type of diabetes } \\
\hline Type I & 64 & 14.2 \\
\hline Type 2 & 390 & 85.8 \\
\hline \multicolumn{3}{|l|}{ Medication } \\
\hline Insulin & 88 & 19.4 \\
\hline Oral hypoglycemic & 315 & 69.3 \\
\hline Both insulin and oral hypoglycemic & 51 & 11.3 \\
\hline \multicolumn{3}{|l|}{ Duration since onset (years) ${ }^{\$}$} \\
\hline$<5$ & 93 & 26.9 \\
\hline$\geq 5$ & 107 & 30.9 \\
\hline $10+$ & 146 & 42.2 \\
\hline \multicolumn{3}{|l|}{ Family history of diabetes } \\
\hline No & 105 & 23.1 \\
\hline Yes & 349 & 76.9 \\
\hline First-degree relatives & $27 \mid$ & 77.7 \\
\hline Second-degree relatives & 47 & 13.5 \\
\hline Both first- and second-degree relatives & 9 & 2.6 \\
\hline More distant relatives & 22 & 6.3 \\
\hline
\end{tabular}

Notes: $\mathrm{n}=454 .{ }^{{ } \mathrm{n}=346}$ cases ( 108 did not remember duration since onset).

participants had been diagnosed with diabetes, $42.2 \%$ had the disease for more than 10 years. Regarding family history of diabetes, $77.7 \%$ of those with a positive history reported a firstdegree relative (ie, a parent or sibling), and $13.5 \%$ reported a second-degree relative with the disease (Table 1).

\section{General and oral health-related awareness and practices \\ General health and oral hygiene practices}

As shown in Table 2, the responses indicated inadequate health-related practices in the surveyed group. Only 13.2\% of participants exercised daily, while $46.5 \%$ rarely exercised and $40.3 \%$ never exercised. Only $30 \%$ of these participants indicated that they had a recent test for blood glucose on the same day of the interview; $10.8 \%$ had a glucose test within 
Table 2 General and oral awareness and practices

\begin{tabular}{|c|c|c|}
\hline Participants' general health and oral hygiene practice & $\mathbf{n}$ & $\%$ \\
\hline \multicolumn{3}{|l|}{ Exercise } \\
\hline Daily & 60 & 13.2 \\
\hline Rarely & 211 & 46.5 \\
\hline None & 183 & 40.3 \\
\hline \multicolumn{3}{|l|}{ Recent glucose test } \\
\hline Today & 136 & 30.0 \\
\hline Last week & 49 & 10.8 \\
\hline Last month & 174 & 38.3 \\
\hline More than a month & 95 & 20.9 \\
\hline \multicolumn{3}{|l|}{ Visited physician for follow-up in the past year } \\
\hline Yes & 364 & 80.2 \\
\hline No & 90 & 19.8 \\
\hline \multicolumn{3}{|l|}{ Dental visits } \\
\hline Regularly & 57 & 12.6 \\
\hline On need & 397 & 87.4 \\
\hline \multicolumn{3}{|l|}{ Brushing frequency } \\
\hline Less than once a day & 36 & 7.8 \\
\hline Once a day & 297 & 65.4 \\
\hline Twice a day & 100 & 22.2 \\
\hline More than twice a day & 21 & 4.6 \\
\hline \multicolumn{3}{|l|}{ Flossing frequency } \\
\hline Never & 334 & 73.6 \\
\hline Occasional & 106 & 23.3 \\
\hline At least once a day & 14 & 3.1 \\
\hline \multicolumn{3}{|l|}{ Ever been told by a health professional to take extra care } \\
\hline To brush teeth & 0 & 0 \\
\hline To see a dentist regularly & 24 & 5.2 \\
\hline \multicolumn{3}{|l|}{ Ever been advised by a dentist to take care and monitor diabetes } \\
\hline Yes & 340 & 74.9 \\
\hline No & 114 & 25.1 \\
\hline \multicolumn{3}{|l|}{ Participants' general diabetes mellitus awareness } \\
\hline \multicolumn{3}{|l|}{ Diet } \\
\hline Patient must eat healthy diet & 436 & 96.0 \\
\hline Patient must eat high-protein diet & 54 & 11.9 \\
\hline Patient must eat high-carbohydrate diet & 199 & 43.8 \\
\hline \multicolumn{3}{|l|}{ Causes of diabetes mellitus } \\
\hline Increase blood sugar level & 362 & 79.7 \\
\hline Body unable to make sugar & 188 & 41.4 \\
\hline Overweight & 370 & 81.5 \\
\hline Eating too much sweets & 88 & 19.4 \\
\hline \multicolumn{3}{|l|}{ Other items } \\
\hline There is only one type of diabetes & 357 & 78.6 \\
\hline A fasting blood glucose of $250 \mathrm{mg} / \mathrm{dL}$ is too high & 335 & 73.8 \\
\hline \multicolumn{3}{|l|}{ Participants' awareness of the association between periodontal disease and diabetes } \\
\hline Diabetics have gum problems more often if their blood sugar remains high & 212 & 46.7 \\
\hline Gum disease makes it harder to control blood sugar in diabetes & 99 & 21.8 \\
\hline Diabetic smokers have more serious gum disease than nonsmokers & 305 & 67.2 \\
\hline People with diabetes are just as likely to get gum disease as people who do not have diabetes & 217 & 47.8 \\
\hline
\end{tabular}

Note: $n=454$.

the last week, and $38.3 \%$ of them had a glucose test within the last month. Although $80.2 \%$ of participants visited a physician for follow-up in the last year, only $12.6 \%$ visited a dentist regularly during the same year.

Regarding oral hygiene practices, the majority of the respondents $(65.4 \%)$ brushed their teeth once a day, $22.2 \%$ brushed their teeth twice a day, and $7.8 \%$ of the respondents brushed their teeth less than once a day. Flossing habits were rated less important as most of the respondents reported that they never flossed their teeth (73.6\%). Regarding health care professionals' involvement in dental care, $94.8 \%$ of respondents reported that they had never received advice on oral hygiene tasks in relation to diabetes from a health professional, and $74.9 \%$ of them stated that their dentists had 
advised them to monitor diabetes. Oral health awareness and advice received are shown in Table 2.

\section{General diabetes mellitus awareness}

As seen in Table 2, the participants' responses were variable regarding the diabetes diet. The majority of the respondents (96\%) responded correctly to the question "Patients must eat a healthy diet", but only $11.9 \%$ responded correctly to the question "Patients must eat a high-protein diet" and 43.8\% responded correctly to the question "Patients must eat a high-carbohydrate diet".

Regarding the causes of diabetes mellitus, $79.7 \%$ responded to the item "increased blood sugar level" correctly, and $41.4 \%$ responded to the item "body unable to make sugar" correctly. Most of the participants' answers were correct (81.5\%) regarding overweight being a cause for diabetes, but only $19.4 \%$ answered correctly as to whether eating too many sweets leads to diabetes.

Approximately $78.6 \%$ of the participants' answers were correct regarding the number of types of diabetes, and $73.8 \%$ could correctly identify that a fasting blood glucose of $250 \mathrm{mg} / \mathrm{dL}$ is too high.

\section{Participants' awareness on the association between periodontal disease and diabetes}

As can be seen in Table 2, nearly half of the participants (46.7\%) knew that diabetics have gum problems more often if their blood sugar stays very high, but only $21.8 \%$ knew that gum disease makes it harder to control blood sugar in diabetic patients. Moreover, the majority of the participants $(67.2 \%)$ knew that people with diabetes who smoke are more likely to develop severe gum disease than nonsmokers with diabetes, and almost half of the participants (47.8\%) knew that people with diabetes are more likely to have periodontal disease than those without diabetes.

\section{Participants' awareness and relationship to healthy behavior}

As shown in Table 3, participants with a higher level of education had significantly greater general awareness about diabetes mellitus $(P=0.000)$ and significantly greater awareness of the association between periodontal disease and diabetes compared to those with school-level education $(P=0.026)$. Those with a longer duration of the disease, those who regularly exercised, those who visited their physicians during the last year, and those who obtained their information from health care providers were significantly more likely to have greater general awareness about diabetes mellitus $(P<0.05)$. In addition, those participants who reported regular dental visits were more likely to be aware of the association between periodontal disease and diabetes $(P<0.05)$.

Regarding source of diabetic-related information, those who obtained their information from health care providers had significantly greater general awareness about diabetes mellitus ( $P=0.000$ ), but awareness of the association between periodontal disease and diabetes was not associated with this source of information $(P=0.075)$. As for the other sources

Table 3 Participants' awareness and healthy behavior

\begin{tabular}{|c|c|c|c|c|c|c|c|c|}
\hline & \multicolumn{3}{|c|}{$\begin{array}{l}\text { General awareness about diabetes } \\
\text { mellitus }\end{array}$} & \multirow[t]{2}{*}{$P$-value } & \multicolumn{3}{|c|}{$\begin{array}{l}\text { Awareness on the periodontal- } \\
\text { diabetes association }\end{array}$} & \multirow[t]{2}{*}{$P$-value } \\
\hline & Median & Minimum & Maximum & & Median & Minimum & Maximum & \\
\hline \multicolumn{9}{|l|}{ Level of education } \\
\hline School level & 55.62 & II.II & 88.92 & $0.000 *$ & 50.0 & 0.0 & 100.0 & $0.026^{*}$ \\
\hline College & 66.71 & 11.11 & 100.00 & & 50.0 & 0.0 & 100.0 & \\
\hline Postgraduate & 66.72 & 33.31 & 100.00 & & 50.0 & 0.0 & 100.0 & \\
\hline \multicolumn{9}{|c|}{ Duration since onset (years) } \\
\hline$<5$ & 66.67 & 11.11 & 88.89 & $0.032 *$ & 50.0 & 0.0 & 100.0 & 0.304 \\
\hline$\geq 5$ & 55.56 & II.II & 100.00 & & 50.0 & 0.0 & 100.0 & \\
\hline $10+$ & 66.67 & II.II & 100.00 & & 50.0 & 0.0 & 100.0 & \\
\hline \multicolumn{9}{|l|}{ Exercise } \\
\hline Daily & 66.67 & 22.22 & 100.00 & $0.000 *$ & 75.0 & 0.0 & 100.0 & 0.065 \\
\hline Rarely & 66.67 & II.II & 100.00 & & 50.0 & 0.0 & 100.0 & \\
\hline None & 55.56 & II.II & 100.00 & & 50.0 & 0.0 & 100.0 & \\
\hline \multicolumn{9}{|c|}{ Physician visits during last year } \\
\hline Yes & 55.56 & II.II & 100.00 & $0.034 *$ & 50.0 & 0.0 & 100.0 & 0.057 \\
\hline No & 55.56 & II.II & 88.89 & & 50.0 & 0.0 & 100.0 & \\
\hline \multicolumn{9}{|l|}{ Dental visit } \\
\hline Regularly & 55.56 & 11.11 & 100.00 & 0.339 & 75.0 & 0.0 & 100.0 & $0.01 I^{*}$ \\
\hline Only when needed & 55.56 & 11.11 & 100.00 & & 50.0 & 0.0 & 100.0 & \\
\hline
\end{tabular}

Note: *Significance level at $P<0.05$. 


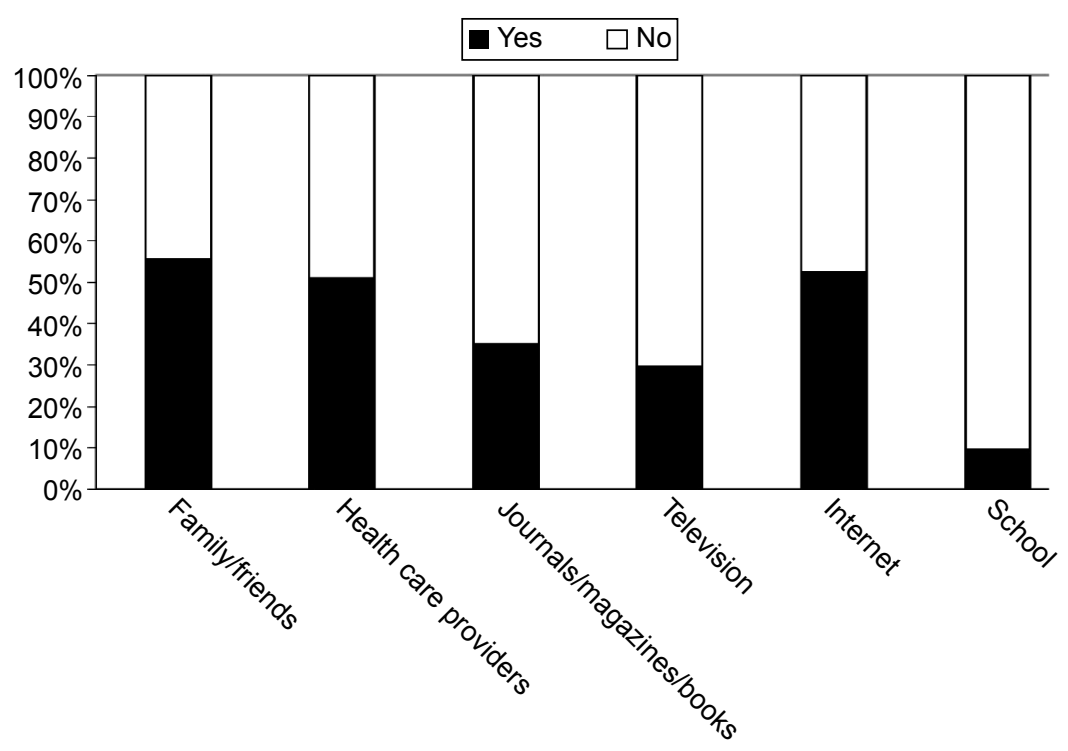

Figure I Sources of diabetes-related information.

of information, the association results were not significant (data not shown).

\section{Sources of diabetes-related information}

All the 454 participants who completed the diabetes awareness assessment questionnaire responded to the question asking how they had learned about diabetes. As shown in Figure 1, more than half of the participants $(55.3 \%)$ had learned about diabetes from family or friends. Just over half got their information from health care providers $(50.9 \%)$. Only $34.8 \%$ of the participants obtained their information from print materials or from television (29.5\%). Over half of the participants learned about diabetes from the Internet (52.2\%), and only 9.3\% gained their information from school.

Participants with a longer duration of disease, those who reported regular exercise, and those who reported regular visits to the physician had more awareness of diabetes mellitus. Participants who reported regular dental visits were more aware of the bilateral association between periodontal disease and diabetes mellitus.

\section{Discussion}

To the best of our knowledge, this is the first study in Saudi Arabia that thoroughly and comprehensively documents diabetic patients' general awareness about diabetes mellitus and its association with periodontal disease, as well as their health behavior and their sources of diabetic-related information.

This study revealed that most of these diabetic participants visited their physician in the last year $(80.2 \%)$, but they were not compliant with dental visits, with only $12.6 \%$ visiting their dentists regularly. The low compliance with regular dental visits shown in the present study is consistent with previous research conducted with female Saudi adults which showed that only $8 \%$ of female diabetic patients visited their dentist on a regular basis ${ }^{20}$ and with another survey conducted with diabetic patients in Jordan that showed only $10 \%$ of participants attended their dental appointments regularly. ${ }^{19}$ Our results regarding dental visit compliance are lower than those reported in other research ${ }^{15,28}$ (39\% and 43\%, respectively). The difference between our study and the latter studies, which were conducted in Western countries, could be due to the different populations investigated.

Based on the participants' physician and dentist visit results, this survey clearly shows that oral health is not a major priority for this particular group of diabetic patients. Moreover, the compliance with dental visits was less than that found in Western countries. Thus, diabetic patients' regular visits to the dentist for reinforcement and education on oral health information should be encouraged in all diabetic centers. Diabetic patients should also be educated about the oral and systemic complications of diabetes, in an effort to meet the national health objective set by the USA, which was by 2010 to increase to $71 \%$ the proportion of people with diabetes who have an annual dental checkup. ${ }^{29}$

The findings that only $22.2 \%$ of the participants brushed their teeth twice daily, only $65.4 \%$ brushed their teeth once daily, and the majority of participants (73.6\%) never used dental floss to clean between their teeth indicate that oral hygiene measures are not a routine practice in this population. 
Therefore, encouragement of proper oral hygiene methods together with education concerning their use should be undertaken in order to enhance periodontal health and prevent gingival diseases in this high-risk population. Similar findings of inadequate oral hygiene in diabetic patients have been shown by other investigators. . $^{19,30,31}$

The findings that none of the participants in this survey had ever been advised by their physicians to brush their teeth and only $5.2 \%$ had received advice from a physician to see their dentist regularly suggest a huge underestimation among physicians of the importance of oral health for diabetic patients. Dentists, physicians, and other health care providers should provide accurate and easily understandable material for diabetic patients about the association between diabetes and oral health and should encourage all diabetic patients to seek oral health examinations. Diabetic patients should be informed that, through preventive oral health measures, periodontal diseases can be minimized or avoided and diabetic control outcomes could be improved.

The results suggest that patients of the diabetic center of the KAU Hospital had considerable awareness of general diabetes information. This awareness of general diabetic items could be attributed to their having regular routine physician visits. However, as for awareness of the relationship of diabetes with periodontal disease, only $68 \%$ of the participants were aware that diabetics would have gum problems more often if their blood sugar remained high. These findings indicate that participants in the present study were less aware regarding the possible connection between periodontal diseases and diabetes and did not recognize that the presence of diabetes increased the risk of periodontal diseases. This lack of awareness of the association between periodontal disease and diabetes within the diabetic group examined is notable, especially in light of their general diabetes awareness. This result was consistent with the results of other studies conducted in Saudi Arabia and other countries showing that knowledge of the relationship of diabetes with periodontal disease is lacking. ${ }^{20,28,32,33}$

Friends and family were the most useful source of information about diabetes (55.3\%), followed by the Internet $(52.2 \%)$. Thus, most of the information obtained by the diabetic patients came from informal sources lacking a scientific basis. This suggests that oral health educational material for diabetic patients containing accurate and updated information needs to be available through educational programs for diabetic patients. However, regardless of the information source, it is clear that the study sample's awareness of the association between periodontal disease and diabetes was limited.
An outcome that was not the main aim of this study was the finding that participants with longer duration of the disease, those who regularly exercised, and those who visited their physicians during the last year were more likely to have greater general awareness about diabetes mellitus. This could be explained by the fact that with longer duration of exposure to health care personnel, patients become more concerned about their medical condition. In addition, those participants who reported regular dental visits were more likely to be aware of the association between periodontal disease and diabetes. This might be attributed to the increased level of attending dental clinics. Similarly, in a study conducted by Al Habashneh et al it was found that diabetic patients with healthier lifestyle behaviors were more likely to have knowledge of the association between diabetes and oral health. ${ }^{19}$ However, findings on dental and physician visits as well as general awareness about diabetes mellitus were not reported in any other previous studies to allow comparison with the present study.

This survey reveals that the awareness of diabetes and periodontal disease is poor. Thus, diabetic patients need to be better informed of their risk for periodontal disease and to have an increased awareness of the importance of oral health in their overall general health and well-being. Improving awareness and thus changing health-related behavior and preventing complications cannot be achieved without health education. Health education attempts to change behaviors by altering an individual's awareness, attitudes, and beliefs about health matters ${ }^{34,35}$ to involve patients in caring for themselves. ${ }^{36}$ Studies on the impact of diabetes health education in terms of metabolic control in Saudi Arabia are very few, and almost all of these studies were conducted to determine the role of knowledge and attending an education program on patients' glycemic control. ${ }^{37-39}$ Therefore, our research findings make it necessary to carry out more research in Saudi Arabia to identify the barriers to awareness and compliance of diabetic patients. Further research could encourage government and private health care providers as well as insurance companies to establish a system that facilitates annual dental visits for all diabetic patients, in keeping with the objectives of the US National Institutes of Healthy People 2010 initiative. ${ }^{40}$

One of the potential causes of patients' lack of awareness might be a lack of knowledge among dentists and physicians regarding the association between periodontal diseases and diabetes mellitus. ${ }^{41}$ Future studies should be conducted in Saudi Arabia to test the knowledge of health care providers on the association between periodontal diseases and diabetes. 
Moreover, it is of paramount importance for dental professionals and health care providers to keep up with current knowledge, since it is fast evolving. ${ }^{42}$ Dental and clinical practitioners should integrate their efforts and participate in education at an organizational level in an effort to raise awareness of oral health issues within the diabetic population.

This study provides many useful and practical insights concerning the factors influencing awareness of the association between diabetes and periodontal health among diabetic patients in Jeddah, Saudi Arabia. This study has three potential limitations. First, we used a nonrandom convenience sample of diabetic patients from the Diabetic Center of KAU Hospital. As such, it is unclear as to what extent the results are representative of diabetic patients in other universitybased clinics or in periodontal practice settings in diverse geographic locations. A more heterogeneous sample from diabetic centers of different hospitals in the region and in other regions in Saudi Arabia would have improved generalization of the results. Second, the results of the study reflect a population with low dental attendance (mainly for symptomatic care). Some bias may have been present in the overall periodontal responses as opposed to general diabetic responses due to the recruitment of the diabetic patients from a diabetic outpatient clinic - the results may therefore not be representative of the whole diabetic population. A third limitation may be the accuracy of the collected data. Data collection was dependent on the participants' responses to the interview questionnaire without review of their medical or dental charts or any official records. Nevertheless, interviewing the participants has an advantage over a self-reported questionnaire in that it avoids their misunderstanding of any questions. No oral examination or laboratory tests were used to ensure validity of the findings. Therefore, our results can hardly be generalized to a broader population with more diverse education, higher levels of oral health knowledge and practice, or more intensive management of the diabetic condition. Finally, answers may be subject to recall bias due to the possibility of participants giving socially acceptable responses to questions pertaining to oral health practice. However, this study provides additional evidence that diabetic patients have limited awareness of the potential impact of poor oral health on their general health.

Despite these limitations, our data suggest that awareness about diabetes and its association with periodontal disease may be limited among diabetic patients. These results support the need for education on the periodontitis-diabetes relationship for these at-risk patients. The clinical implication of our findings is that dentists, physicians, and other health providers should recommend that a diabetic patient see a dentist regularly. Dental practitioners have an opportunity and a responsibility to educate diabetic patients about the oral complications of diabetes and to promote proper oral health behaviors. Future patient education requires ingenuity and the commitment of necessary resources to improve outcomes with diabetic patients.

\section{Conclusion}

These findings of limited awareness regarding diabetes and periodontitis indicate that this topic is still neglected, and immediate actions should be taken.

\section{Acknowledgments}

This work was funded by the Deanship of Scientific Research (DSR), KAU, Jeddah, under grant number (165-697-D1435). The author, therefore, acknowledges with thanks DSR technical and financial support.

\section{Disclosure}

The author reports no conflict of interest in this work.

\section{References}

1. Wild S, Roglic G, Green A, Sicree R, King H. Global prevalence of diabetes: estimates for the year 2000 and projections for 2030. Diabetes Care. 2004;27(5):1047-1053.

2. Al-Nozha MM, Al-Maatouq MA, Al-Mazrou YY, et al. Diabetes mellitus in Saudi Arabia. Saudi Med J. 2004;25(11):1603-1610.

3. Gadsby R. Epidemiology of diabetes. Adv Drug Deliv Rev. 2002; 54(9):1165-1172.

4. Campus G, Salem A, Uzzau S, Baldoni E, Tonolo G. Diabetes and periodontal disease: a case-control study. J Periodontol. 2005;76(3):418-425.

5. Cohen DW, Friedman LA, Shapiro J, Kyle GC, Franklin S. Diabetes mellitus and periodontal disease: two-year longitudinal observations. I. J Periodontol. 1970;41(12):709-712.

6. Emrich LJ, Shlossman M, Genco RJ. Periodontal disease in non-insulindependent diabetes mellitus. J Periodontol. 1991;62(2):123-131.

7. Seppala B, Seppala M, Ainamo J. A longitudinal study on insulindependent diabetes mellitus and periodontal disease. J Clin Periodontol. 1993;20(3):161-165.

8. Shlossman M, Knowler WC, Pettitt DJ, Genco RJ. Type 2 diabetes mellitus and periodontal disease. J Am Dent Assoc. 1990;121(4):532-536.

9. Collin HL, Uusitupa M, Niskanen L, et al. Periodontal findings in elderly patients with non-insulin dependent diabetes mellitus. J Periodontol. 1998;69(9):962-966.

10. Grossi SG, Genco RJ. Periodontal disease and diabetes mellitus: a two-way relationship. Ann Periodontol. 1998;3(1):51-61.

11. Iacopino AM. Periodontitis and diabetes interrelationships: role of inflammation. Ann Periodontol. 2001;6(1):125-137.

12. Boehm TK, Scannapieco FA. The epidemiology, consequences and management of periodontal disease in older adults. J Am Dent Assoc. 2007; 138:26S-33S.

13. Lang WP, Ronis DL, Farghaly MM. Preventive behaviors as correlates of periodontal health status. J Public Health Dent. 1995;55(1):10-17.

14. Maung MT. Dental Care for Diabetics. South African Diabetes Association [website on the Internet]; 2001. Available from: http:// www.home.intekom.com/buildlink/ips/sada/dental.htm/. Accessed December, 2014. 
15. Sandberg GE, Sundberg HE, Wikblad KF. A controlled study of oral self-care and self-perceived oral health in type 2 diabetic patients. Acta Odontol Scand. 2001;59(1):28-33.

16. Tomar SL, Lester A. Dental and other health care visits among U.S. adults with diabetes. Diabetes Care. 2000;23(10):1505-1510.

17. Moore PA, Orchard T, Guggenheimer J, Weyant RJ. Diabetes and oral health promotion: a survey of disease prevention behaviors. J Am Dent Assoc. 2000;131(9):1333-1341.

18. Karikoski A, Ilanne-Parikka P, Murtomaa H. Oral self-care among adults with diabetes in Finland. Community Dent Oral Epidemiol. 2002; 30(3):216-223.

19. Al Habashneh R, Khader Y, Hammad MM, Almuradi M. Knowledge and awareness about diabetes and periodontal health among Jordanians. J Diabetes Complications. 2010;24(6):409-414.

20. Awartin F. Oral health knowledge and practices in Saudi diabetic female patients. PODJ. 2009;29(1):149-152.

21. Ismael FMR, Ali N. Diabetic patients knowledge, attitude and practice toward oral health. J Educ Prac. 2013;4(20):19-25.

22. American Academy of Periodontology. Diabetes and Periodontal Disease; 2014. Available from: http://www.perio.org/consumer/diabetes. $\mathrm{htm} /$. Accessed December, 2014.

23. American Diabetes Association. Standards of medical care in diabetes 2011. Diabetes Care. 2011;34(1):S11-S61.

24. American Diabetes Association. Diabetes Basics. Diabetes Myths 2014. Available from: http://www.diabetes.org/diabetes-basics/myths/. Accessed December, 2014.

25. Centers for Disease Control and Prevention. National Diabetes Fact Sheet. Atlanta, GA: Centers for Disease Control and Prevention; 2011.

26. National Diabetes Information Clearinghouse. Prevent Diabetes Problems: Keep Your Teeth and Gums Health; 2014. Available from: http://diabetes.niddk.nih.gov/dm/pubs/complications_teeth/. Accessed December, 2014.

27. National Institute of Dental and Craniofacial Research. Diabetes: Dental Tips. Bethesda, MD: NIH; 2014.

28. Allen EM, Ziada HM, O’Halloran D, Clerehugh V, Allen PF. Attitudes, awareness and oral health-related quality of life in patients with diabetes. J Oral Rehabil. 2008;35(3):218-223.

29. Centers for Disease Control and Prevention (CDC). Dental visits among dentate adults with diabetes - United States, 1999 and 2004. MMWR Morb Mortal Wkly Rep. 2005;54(46):1181-1183.
30. Bakhshandeh S, Murtomaa H, Vehkalahti MM, Mofid R, Suomalainen K. Oral self-care and use of dental services among adults with diabetes mellitus. Oral Health Prev Dent. 2008;6(4):279-286.

31. Eldarrat AH. Awareness and attitude of diabetic patients about their increased risk for oral diseases. Oral Health Prev Dent. 2011;9(3): 235-241.

32. Jansson H, Lindholm E, Lindh C, Groop L, Bratthall G. Type 2 diabetes and risk for periodontal disease: a role for dental health awareness. J Clin Periodontol. 2006;33(6):408-414.

33. Masood Mirza K, Khan AA, Ali MM, Chaudhry S. Oral health knowledge, attitude, and practices and sources of information for diabetic patients in Lahore. Pak Diabetes Care. 2007;30(12):3046-3047.

34. Morgan R, Tsang J, Harrington N, Fook L. Survey of hospital doctors' attitudes and knowledge of oral conditions in older patients. Postgrad Med J. 2001;77(908):392-394.

35. Tsai C, Hayes C, Taylor GW. Glycemic control of type 2 diabetes and severe periodontal disease in the US adult population. Community Dent Oral Epidemiol. 2002;30(3):182-192.

36. World Health Organization. Management of Diabetes Mellitus: Standards of Care and Clinical Practice Guidelines; 1994. Available from: http://applications.emro.who.int/dsaf/dsa664.pdf/. Accessed December, 2014.

37. Al-Shahrani AM,Hassan A, Al-RubeaanKA, AlSharqawi AH, AhmadNA. Effects of diabetes education program on metabolic control among Saudi type 2 diabetic patients. Pak J Med Sci. 2012;28(5):925-930.

38. El-Zubier AG, Aladin A, Al-Amri JB, Al-Haraka EA, Abu-Samara IO Self-care, self-reliance and knowledge of diabetes among diabetes in Qassim region. Saudi Med J. 1996;17:598-603.

39. Uddin I, Ahmad TJ, Kurkuman AR, Iftikhar R. Diabetes education: its effects on glycemic control. Ann Saudi Med. 2001;21(1-2):120-122.

40. Office of the Disease Prevention and Health Promotion. Healthy People 2010; 2010. Available from: http://www.cdc.gov/nchs/healthy_people/ hp2010.htm. Accessed December, 2014.

41. Al-Khabbaz AK, Al-Shammari KF, Al-Saleh NA. Knowledge about the association between periodontal diseases and diabetes mellitus: contrasting dentists and physicians. J Periodontol. 2010;82(3):360-366.

42. Strauss SM, Singh G, Tuthill J, et al. Diabetes-related knowledge and sources of information among periodontal patients: is there a role for dental hygienists? J Dent Hyg. 2013;87(2):82-89.
Patient Preference and Adherence

\section{Publish your work in this journal}

Patient Preference and Adherence is an international, peer-reviewed, open access journal that focuses on the growing importance of patient preference and adherence throughout the therapeutic continuum. Patient satisfaction, acceptability, quality of life, compliance, persistence and their role in developing new therapeutic modalities and compounds to optimize

\section{Dovepress}

clinical outcomes for existing disease states are major areas of interest for the journal. This journal has been accepted for indexing on PubMed Central. The manuscript management system is completely online and includes a very quick and fair peer-review system, which is all easy to use. Visit http://www. dovepress.com/testimonials.php to read real quotes from published authors. 